\title{
Design of a Microgrid with Low-Voltage Ride-Through Capability and Simulation Experiment
}

\author{
Wenchao Fan, Zaijun Wu, Xiaobo Dou, Minqiang Hu, Jieru Wei, and Zhenyu Lv \\ School of Electrical Engineering, Southeast University, Nanjing 210096, China \\ Correspondence should be addressed to Zaijun Wu; 357924813@qq.com
}

Received 24 January 2014; Revised 10 May 2014; Accepted 12 May 2014; Published 9 June 2014

Academic Editor: Hongjie Jia

Copyright ( 2014 Wenchao Fan et al. This is an open access article distributed under the Creative Commons Attribution License, which permits unrestricted use, distribution, and reproduction in any medium, provided the original work is properly cited.

\begin{abstract}
A microgrid with low-voltage ride-through capability is designed. The designed microgrid avoids operating in unplanned islanded mode during an asymmetric ground fault which occurs in the low voltage distribution network and supports fault recovery for distribution network. Furthermore, compared with the traditional microgrid topology, the proposed microgrid topology also saves a lot of power electronic devices. The simulation results with PSCAD/EMTDC show that the microgrid can keep the distributed generations and loads operate normally when an asymmetric ground fault occurs in the low voltage distribution grid. It can also increase the active power output according to the requirement of the distribution network to support the distribution network fault recovery.
\end{abstract}

\section{Introduction}

With the gradual depletion of fuel energy, renewable energy, such as wind power and solar power, is attracting more and more attention. In order to achieve effective utilization of renewable energy and improve the power supply reliability, the microgrid concept is proposed. Microgrid is a small system which contains distributed generations (DGs), energy storage devices, loads, protection equipment, and communication equipment. With the microgrid accessing distribution network, the power flow changes from one direction to bidirection. So that it had a profound impact on distribution network's load forecasting, plan, protection, and other issues [1].

According to the national regulation codes, microgrid should be disconnected from the distribution network shortly when a fault occurs in the distribution network. Hence, the microgrid operation will be transferred from gridconnected mode to islanded mode in order to ensure that the sensitive loads operate normally. This transition is not planed in advance, so it is called nonplanned islanded mode. That microgrid operates in nonplanned islanded mode will cause a lot of adverse consequences. When the microgrid disconnects from the distribution network, power flow through the point of common coupling (PCC) will reduce to zero. For the distribution network, it will cause the line voltage's amplitude and frequency fluctuate and even expand the failure scope or reduce the accuracy of protective equipment. At this time, the microgrid disconnects from network which will lead its internal power to an unbalanced status. Short-time power imbalance in microgrid may demand loads or DGs to disconnect from distribution network. If the power cannot reach equilibrium in a certain time, power imbalance may even lead to the system crash, threatening the loads' normal operation. To solve this problem, we should take some measurements to make the microgrid operation remain in connection mode when some fault occurs in the distribution network. Common distribution network asymmetric ground fault mainly consists of two-phase ground fault and singlephase ground fault. They account for more than $90 \%$ of the total distribution network fault. So we focused on these faults, developed microgrid topology and its control strategies in order to render that the microgrid acquires a low-voltage ride-through (LVRT) capability when the above faults occur in distribution network.

\section{Design of the Entire System}

In order to achieve the above objectives, the microgrid with LVRT capability was designed. The topology is shown in 


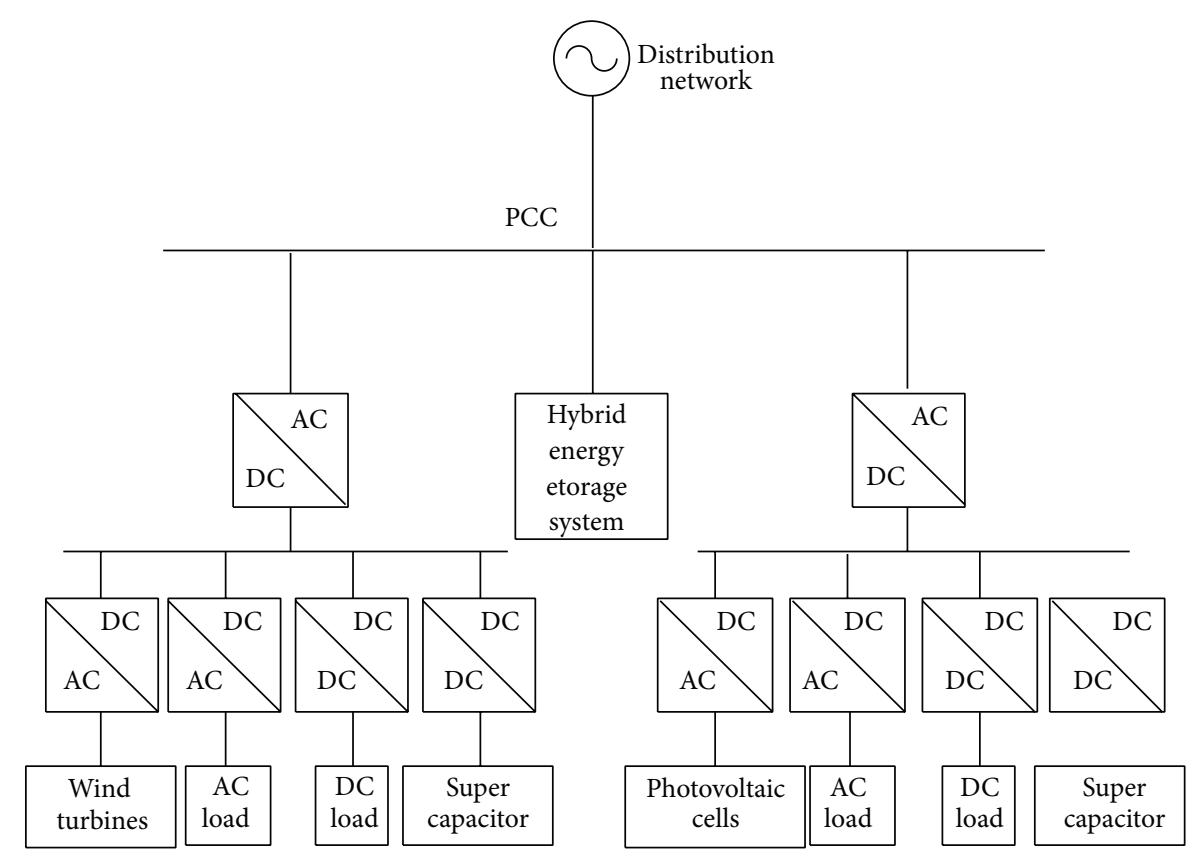

FIgURE 1: Design of the entire system.

Figure 1. Different from the traditional topology, the designed microgrid is mainly composed of two sub-microgrids. Each sub-microgrid is essentially a DC microgrid, which contains a DG, a storage device, a DC load, and an AC load. The two sub-microgrids' micropowers are direct-driven wind turbine generators and photovoltaic cells, respectively. They are named as sub-microgrid $\mathrm{A}$ and sub-microgrid B. Each sub-microgrid's DC load and AC load connect to the DC bus through converters. Each of the sub-microgrid's energy storage system is mainly composed of a super capacitor, which connects to the DC bus through DC-DC converter. When the microgrid operates normally, super capacitor can coordinate sub-microgrid's internal power. When the submicrogrid DC bus voltage changes because of an asymmetric ground fault in the distribution network, super capacitor absorbs energy to maintain it. Super capacitor can ensure that the micropower and load operate normally when an asymmetric ground fault occurs in the distribution network, avoiding the microgrid operating in nonplanned islanded mode.

There is also a hybrid energy storage system connecting in main microgrid feeder. It consists of storage batteries and super capacitors. During the microgrid operation in LVRT state, the energy storage system not only can stabilize power fluctuations near PCC but also issue an appropriate amount of power according to the distribution grid requirements to provide support for the distribution network fault recovery.

\section{Design of the Sub-Microgrid's Converter Control System}

For direct-driven wind turbine generators system, distribution network carrying an asymmetric ground fault can cause

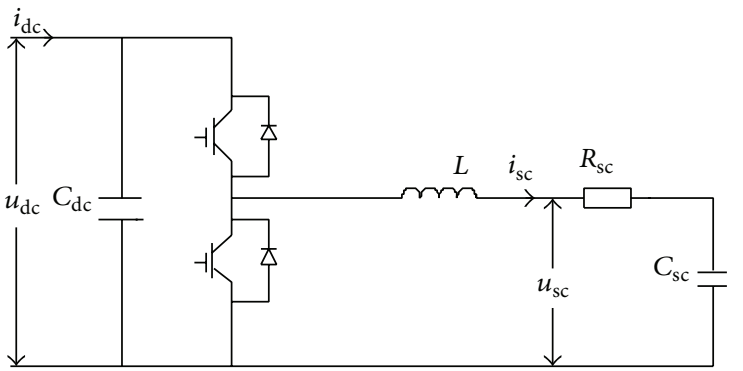

FIGURE 2: Circuit structure of super capacitor energy storage system.

its power output to reduce, which will lead its DC bus voltage to drop. This phenomenon can also generate second power harmonic in power output, which can cause the DC bus voltage fluctuates at a frequency twice of the power frequency, destabilizing the entire system [2].

Similar to direct-driven wind turbine generators, the microgrid main feeder voltage drop when an asymmetric ground fault occurs in the distribution network. So it can also result in the sub-microgrid DC bus voltage increasing and fluctuating. To solve such problems, super capacitor energy storage devices were installed in each sub-microgrid. They connect to the sub-microgrid DC bus through the buck-boost DC/DC conversion circuit. This topology's main advantage is that it can achieve a steady DC bus voltage during the microgrid operation in LVRT status.

3.1. Design of the Super Capacitor Bidirectional Buck-Boost Converter Control System. Figure 2 is a simplified circuit structure of super capacitor energy storage system. The super capacitor is simplified for a model, which contains 


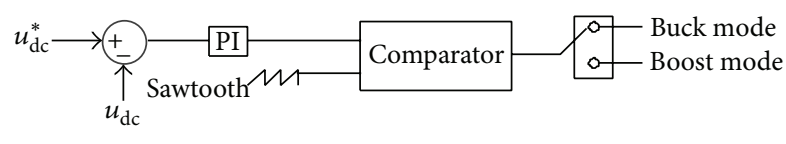

FigURE 3: Bidirectional converter control system.

capacitance and resistance in series. The energy storage system connects to the sub-microgrid DC bus through the bidirectional buck-boost converter.

Super capacitor bidirectional buck-boost converter control system diagram is shown in Figure 3.

As shown in Figure 3, first of all, by subtracting submicrogrid DC bus voltage's actual value from its set-point value, an output signal will be obtained. Secondly, after being adjusted by the PI regulator, the output signal was compared with a preset sawtooth through comparator. Then a result is obtained, which decides the converter work mode: buck mode or boost mode. The operation mode of the super capacitor is actually decided by the variety of the exchange power between sub-microgrid and microgrid main feeder [3]. The difference between the DG's exporting power and the load's wasting power is transported to the microgrid, which is set as $P_{\text {out }}$. In this system, we assume $P_{\text {out }}$ is positive when the microgrid operates normally. If an asymmetric ground fault occurs in the distribution network, microgrid main feeder voltage will drop. Furthermore, due to the fact that the current flowing through the grid-connected inverter is limited, the power flowing through it will decline. So there is excess energy in sub-microgrid which cannot be transferred out, causing the DC bus voltage to rise. In this case, the converter operates in buck model, absorbing excess energy to maintain the DC bus voltage. If the DC bus voltage decreases for some reasons, the converter will operate in boost mode, releasing energy. Since energy can flow in both directions, this control topology can take some effect to stabilize the DC bus voltage.

Assume that the imbalance power in sub-microgrid is $\Delta P$. According to Figure 2, it can be expressed as

$$
\Delta P=u_{\mathrm{dc}} i_{\mathrm{dc}} .
$$

According to Figure 2, the following equations are obtained:

$$
\begin{gathered}
C_{\mathrm{sc}} \frac{d\left(u_{\mathrm{sc}}-i_{\mathrm{sc}} R_{\mathrm{sc}}\right)}{d t}=i_{\mathrm{sc}}, \\
i_{\mathrm{dc}}=D i_{\mathrm{sc}} .
\end{gathered}
$$

In (3), D is the duty cycle. Combine (1), (2), and (3), and the following is obtained:

$$
u_{\mathrm{sc}}=\frac{1}{D} \frac{\Delta P}{C_{\mathrm{sc}} u_{\mathrm{dc}}} t .
$$

Assume that an initial voltage of the super capacitor is $u_{\text {ini }}$, and the maximum allowable voltage is $u_{\max }$. According to (4), a maximum low-voltage riding time which can be maintained by the super capacitor is

$$
T_{\max }=\frac{D\left(u_{\max }-u_{\mathrm{ini}}\right) C_{\mathrm{sc}} u_{\mathrm{dc}}}{\Delta P} .
$$

Despite the fact that $\Delta P$ fluctuates when the system operates in LVRT status, its average value can stay stable. So formula (5) is reasonable. The super capacitor under this control method can maintain the DC bus voltage, avoiding adverse effects on the DG and making loads operate normally when an asymmetrical ground fault occurs in the distribution network.

3.2. Design of Load Side Inverter Control System. In this system, load side inverters connect to the sub-microgrid DC bus. As long as the DC bus voltage stays stable, the DC load can operate normally and reduce the impact on the AC load when an asymmetric ground fault occurs in the distribution network. The DC load connects to DC bus through DC-DC buck chopper. The topology's aim is to maintain the DC load voltage stable.

Due to the occurrence of an asymmetric ground fault in the distribution network, the sub-microgrid's current output will change, which can lead to its DC bus current change. In this case, despite the fact that the DC bus voltage stays stable, the ripple current can still affect the AC load's normal operation. Hence, outer power loop and inner current loop control system are designed, which is shown in Figure 4.

$P_{\text {Lref }}$ and $Q_{\text {Lref }}$ are the load rated active and reactive powers, respectively. As set-points active power value and reactive power value, they minus actual active power value and reactive power value respectively. After being adjusted by PI regulation, the results are considered the given value of active component and reactive component of the load current. Then collect three-phase load current. Active component $i_{\text {Ldref }}$ and reactive component $i_{\text {Lqref }}$ will be obtained by coordinate transformation. Then they subtract the given values, respectively. Having been adjusted by PI regulation, the results are considered as the active component and reactive component of load voltage. They are also considered as the inverter drive signals.

\section{Design of Sub-Microgrid Grid-Connected Inverter Control System}

As mentioned above, the microgrid main feeder voltage drop will lead the sub-microgrid power output to fluctuate. In order to suppress the fluctuations and reduce the impact on the DC bus voltage during the microgrid operation in LVRT status, proportional integral resonant (PIR) regulator is applied to replace proportional integral (PI) regulator in sub-microgrid's grid-connected inverter control system.

The resonant regulator was proposed according to the principle that the control system has no steady error when it directly controls the DC signal in the two-phase rotating coordinate system [4-6].

The transfer function of PIR controller used in the system is

$$
G(s)=k_{p}+\frac{k_{i}}{s}+\frac{k_{r} s}{1+2 \omega_{c} s+\left(2 \omega_{s}\right)^{2}} .
$$




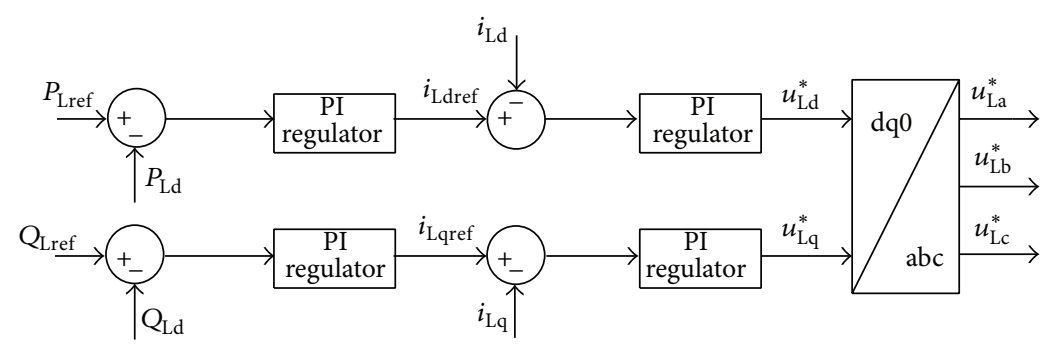

FIGURE 4: Load side inverter control system.

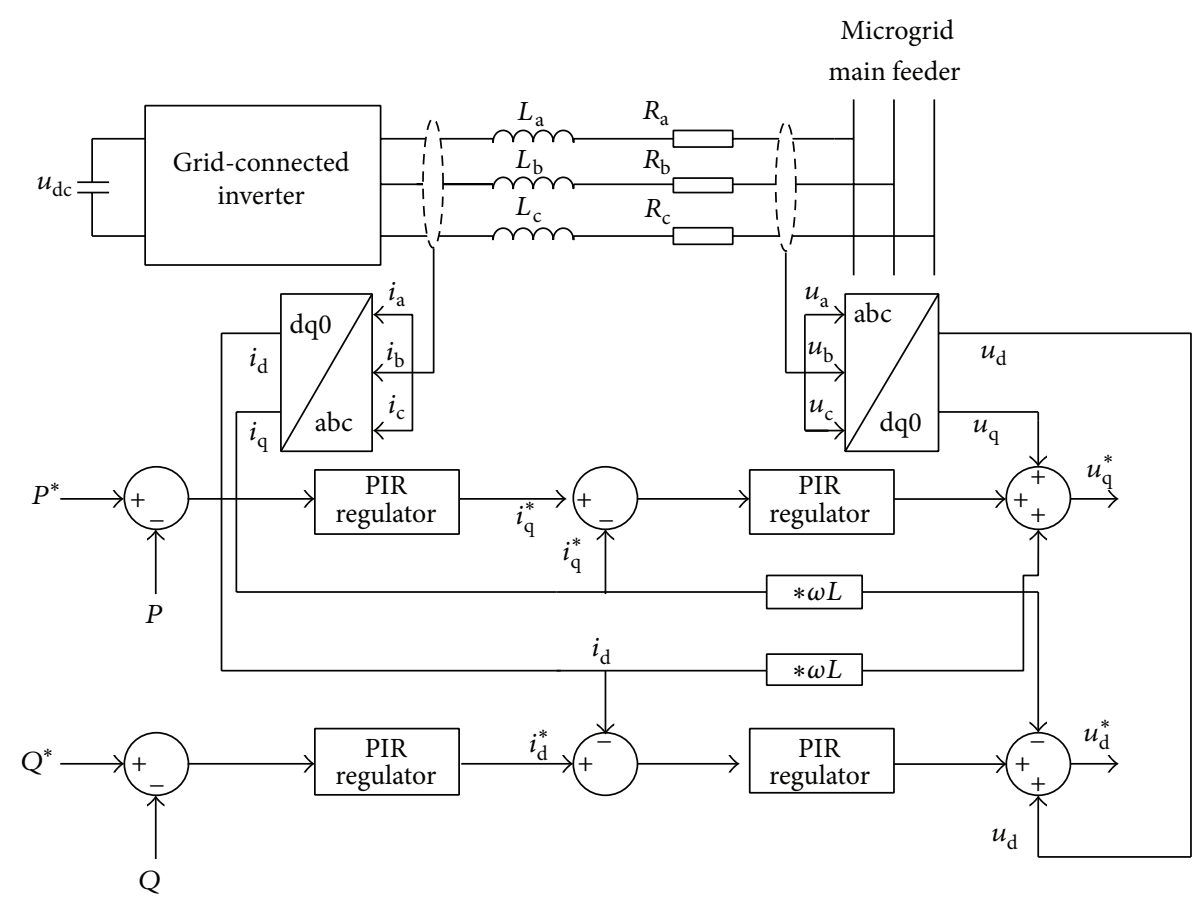

FIGURE 5: Sub-microgrid inverter control system.

In this formula, $\omega_{c}$ is the resonant regulator's cutoff frequency, which determines the bandwidth of the resonant regulator. $\omega_{s}$ is the resonant regulator's angular frequency, which is the same with the grids for $314 \mathrm{rad} / \mathrm{s}$. For this system, when the signal passes through this function, the section whose angular frequency is $618 \mathrm{rad} / \mathrm{s}$ will be amplified, while other sections will be suppressed. Set the appropriate gain $k_{r}$. Then the function can compensate for power harmonics whose frequency is twice of the fundamentals to achieve the purpose of suppressing the sub-microgrid power output fluctuations.

Constant-power control strategy is utilized in the submicrogrid grid-connected inverter. The control system consists of outer power loop and inner current loop, which is shown in Figure 5.

In outer power loop, set-point power values minus actual ones respectively and the results will be obtained. After being adjusted by PIR regulator, they are considered as corresponding given current signals for inner current loop. Their expressions are as follows:

$$
\begin{aligned}
& i_{d}^{*}=\left(P^{*}-P\right)\left(k_{p}+\frac{k_{i}}{s}+\frac{k_{r} s}{s^{2}+2 \omega_{c} s+\left(2 \omega_{s}\right)^{2}}\right), \\
& i_{q}^{*}=\left(Q^{*}-Q\right)\left(k_{p}+\frac{k_{i}}{s}+\frac{k_{r} s}{s^{2}+2 \omega_{c} s+\left(2 \omega_{s}\right)^{2}}\right) .
\end{aligned}
$$

As aforementioned, microgrid power output fluctuates when the main feeder voltage drops. This phenomenon can be attributed to the current's DC component fluctuations in $d q$ coordinate system. Suppressing it actually has a great benefit in inhibiting the power output fluctuations. Hence, the PI controller should also be replaced by PIR controller in the inner current loop. Then the system forms a double resonant controller structure, which will play better in suppressing the sub-microgrid power output fluctuations. The voltage 


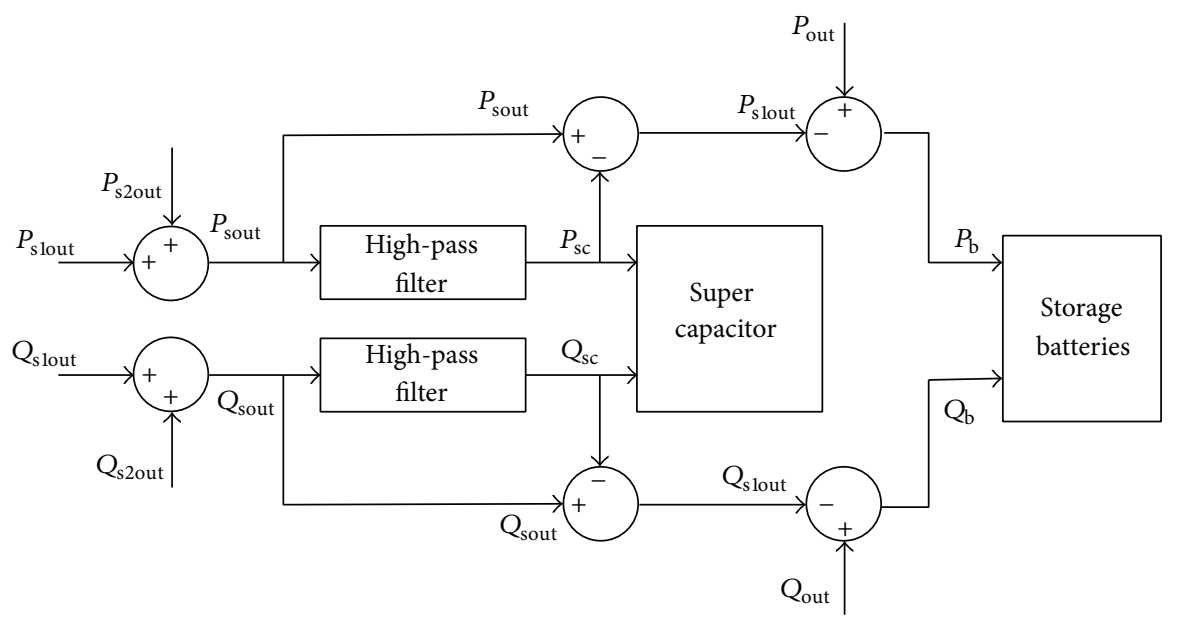

FIGURE 6: Hybrid energy storage control system.

reference signals generate from inner current loop are as follows:

$$
\begin{aligned}
& U_{d}^{*}=\left(i_{d}^{*}-i_{d}\right)\left(k_{p}+\frac{k_{i}}{s}+\frac{k_{r} s}{s^{2}+2 \omega_{c} s+\left(2 \omega_{s}\right)^{2}}\right)-\omega L i_{q}+U_{d} \\
& U_{q}^{*}=\left(i_{q}^{*}-i_{q}\right)\left(k_{p}+\frac{k_{i}}{s}+\frac{k_{r} s}{s^{2}+2 \omega_{c} s+\left(2 \omega_{s}\right)^{2}}\right)+\omega L i_{d}+U_{q} .
\end{aligned}
$$

\section{Design of the Microgrid Hybrid Energy Storage System}

As mentioned above, when an asymmetric ground fault occurs in distribution network, its exchange power with the microgrid will reduce instantly. This phenomenon has some impact on the distribution network even expands the fault area in distribution network. Despite the fact that the PIR regulators are utilized in the system to inhibit harmonic power when the microgrid operates in LVRT status, it is not completely eliminated. Harmonic power injected into the distribution network will cause adverse effects for the distribution network fault recovery. Finally, according to the energy storage system's grid-connected inverter power output limitation and the requirement of cooperation with the distribution network protection devices and others, the power values, which should be exported from the microgrid to distribution network during the system operation in LVRT status, are set.

During the microgrid operation in connection mode, the hybrid energy storage system on the microgrid main feeder is in floating mode, almost having no action. When the microgrid operates in LVRT status, the hybrid energy storage system has two main roles. First, increase the power output to compensate for the reduced microgrid's power output and provide additional active power for distribution network fault recovery. Second, stabilize power on the main feeder, making the power passing through PCC as smooth as possible to reduce the harmonic power's adverse effects on distribution network.

To achieve the above aims, the hybrid energy storage control system is designed as dual-loop control structure, which is shown in Figure 6 [7].

First of all, collect the two sub-microgrids' power outputs $P_{\text {s1out }}, Q_{\text {slout }}, P_{\text {s2out }}$, and $Q_{\text {s2out }}$. As shown in Figure 6, add $P_{\text {s1out }}$ to $P_{\text {s2out }}$ and $Q_{\text {s1out }}$ to $Q_{\text {s2out }}$, respectively. We can obtain the values of the sub-microgrids' total active power output $P_{\text {sout }}$ and reactive power output $Q_{\text {sout }}$. Secondly, design a highpass filter, and offer $P_{\text {sout }}$ and $Q_{\text {sout }}$ to pass through it. Then we obtain the high frequency elements of the two microgrids' total active power output signal $P_{\mathrm{sc}}$ and reactive power output signal $Q_{s c}$. They are utilized as the super capacitor power output command, which can stabilize power in main feeder. At the same time, subtract $P_{\mathrm{sc}}$ from $P_{\text {sout }}$. We will obtain low frequency component of the two sub-microgrids' total active power output $P_{\text {slout }}$. With the same method, the low frequency component of their total reactive power output can also be obtained. Finally, according to the energy storage system's grid-connected inverter power output limitation and the requirement of cooperation with the distribution network protection devices and others, make sure the power values $P_{\text {out }}$ and $Q_{\text {out }}$, which should export from the microgrid to distribution network during the system operation in LVRT status. Make the difference between $P_{\text {out }}$ and $P_{\text {slout }}$ and the difference between $Q_{\text {out }}$ and $Q_{\text {slout }}$, respectively. The results are utilized as the storage given power output signals $P_{b}$ and $Q_{b}$. As long as the power output tracks the command value, it not only can keep the power passing PCC stable but also can help the distribution network to restore to normal as soon as possible.

\section{Simulation Analysis}

At the present time, China has no LVRT requirements for DG connecting in distribution network of $0.4 \mathrm{kV}$. However, with the large-scale application of microgrid in distribution network, it's a trend to make microgrid acquire a LVRT 


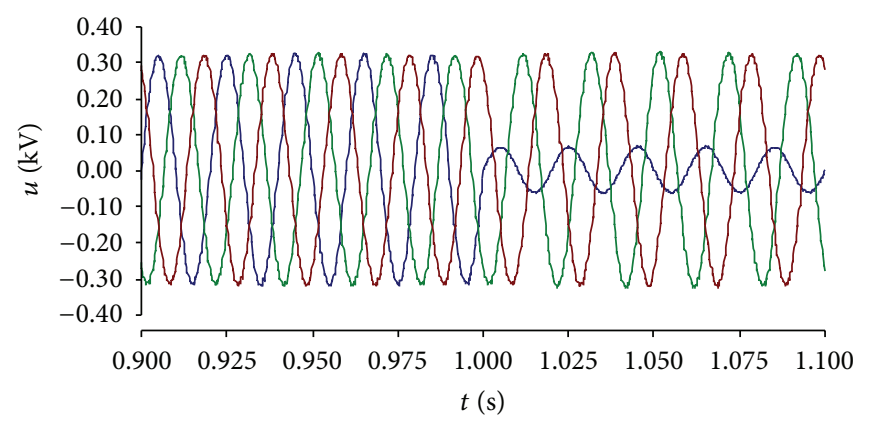

(a)

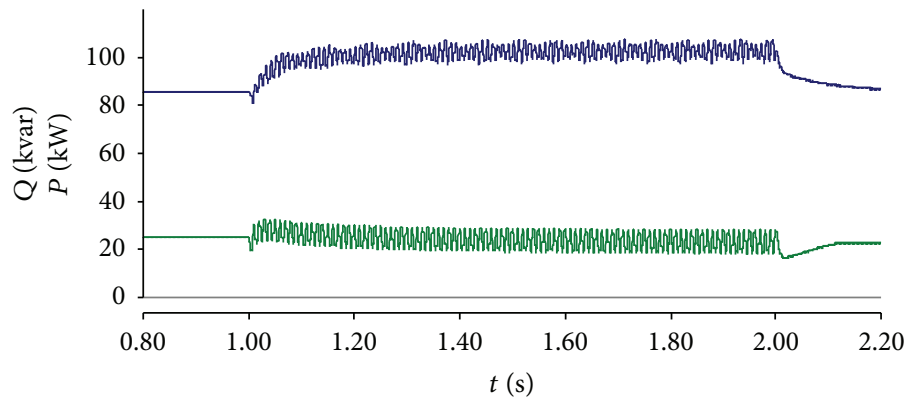

(b)

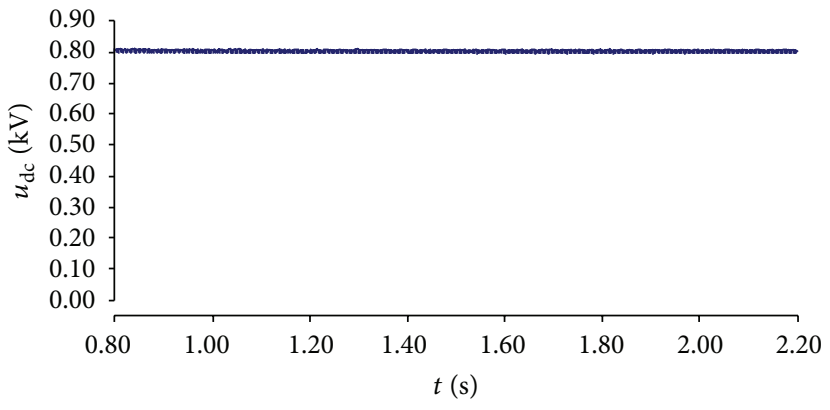

(c)

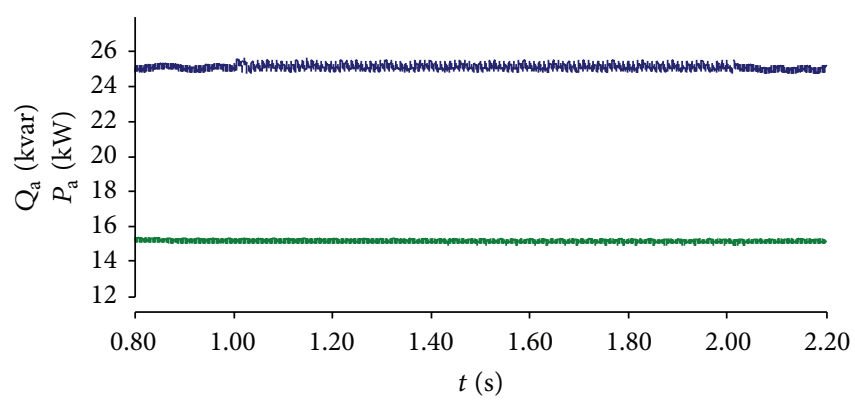

(d)

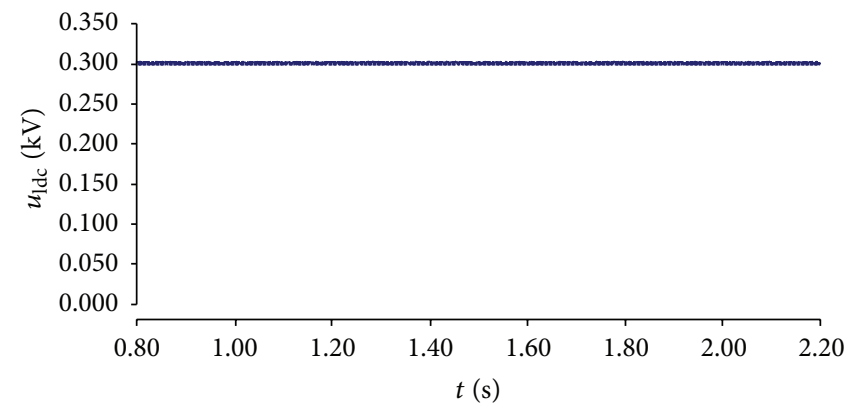

(e)

FiguRE 7: (a) Microgrid main feeder voltage waveform under single-phase ground fault in distribution network. (b) Microgrid exporting power waveform under single-phase ground fault in distribution network. (c) DC bus voltage waveform of sub-microgrid A under singlephase ground fault in distribution network. (d) AC load power waveform of sub-microgrid A under single-phase ground fault in distribution network. (e) DC load voltage waveform of sub-microgrid A under single-phase ground fault in distribution network.

capability in low voltage distribution network to eliminate the threat of the microgrid non-planned islanded mode on itself normal operation and to provide support for the distribution network recovery when an asymmetrical ground fault occurs in it.
Based on this, we built a system model in PSCAD/ EMTDC simulation software to do simulation experiments. We set the microgrid's rated active power output as $85 \mathrm{~kW}$ and reactive power output as $25 \mathrm{kvar}$ during the system normal operation. Sub-microgrid A's rated active power output is 


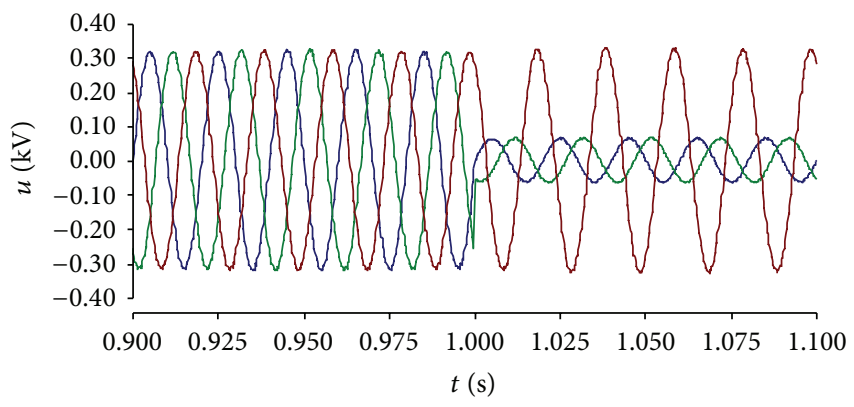

(a)

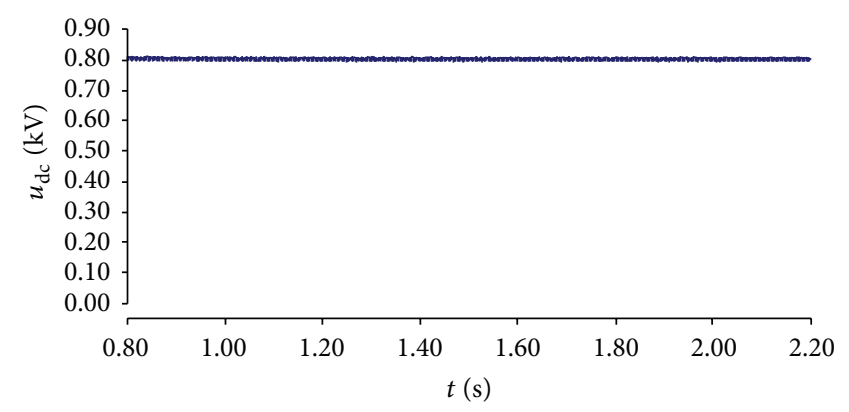

(c)

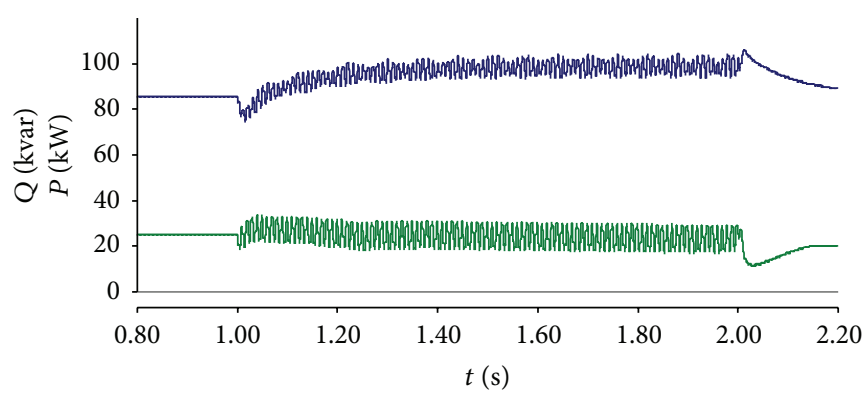

(b)

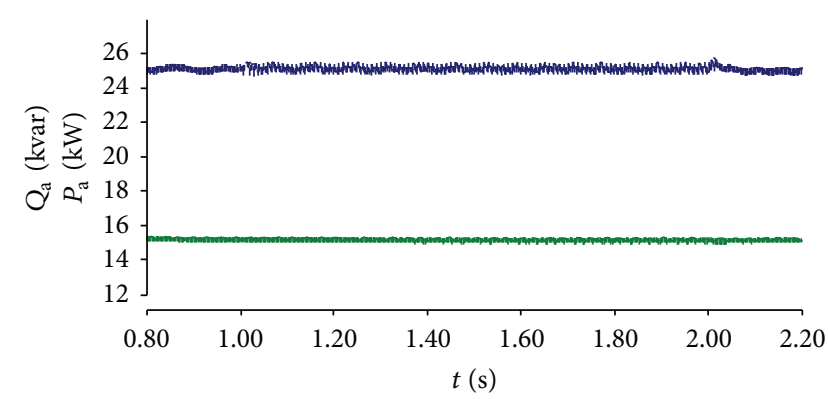

(d)

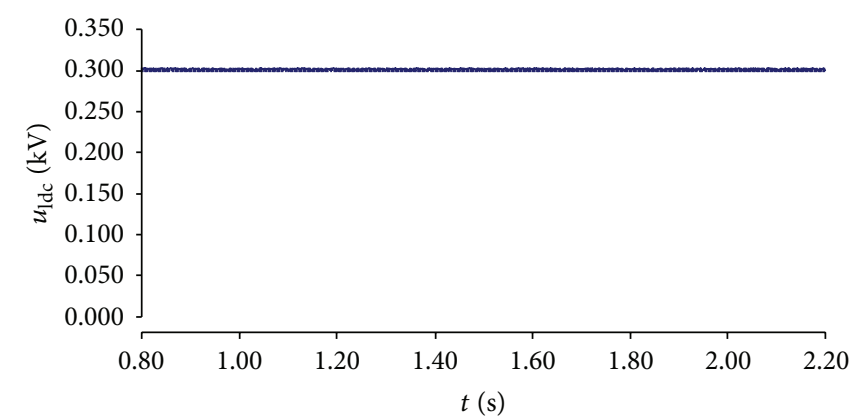

(e)

FIGURE 8: (a) Microgrid main feeder voltage waveform under two-phase ground fault in distribution network. (b) Microgrid exporting power waveform under two-phase ground fault in distribution network. (c) DC bus voltage waveform of sub-microgrid A under two-phase ground fault in distribution network. (d) AC load power waveform of sub-microgrid A under two-phase ground fault in distribution network. (e) DC load voltage waveform of sub-microgrid A under two-phase ground fault in distribution network.

$50 \mathrm{~kW}$ and reactive power output is $15 \mathrm{kvar}$. Sub-microgrid B's rated active power output is $35 \mathrm{~kW}$ and reactive power output is $10 \mathrm{kvar}$. Take the sub-microgrid A, for example, analyzed of the effect of sub-microgrid control system. Set DC bus voltage-stabilized capacitor as $6000 \mu \mathrm{F}$, DC bus rated voltage as $0.8 \mathrm{kV}$, DC load rated voltage as $0.3 \mathrm{kV}$, DC load rated power as $90 \mathrm{~kW}$. Set DC-DC converter control system's PI regulator parameters $P=15$ and $I=0.02$. AC loads rated line voltage is $0.38 \mathrm{kV}$, rated active power is $25 \mathrm{~kW}$, and rated reactive power is $15 \mathrm{kvar}$. Active power control component of the AC load control system has the same PI regulator parameters with the reactive power control component. Current inner loop PI regulator parameters are $P=10$ and $I=0.1$, and power outer loop PI regulator parameters are $P=10$ and $I=0.1$. Grid-connected inverter filter capacitor is $C=12 \mu \mathrm{F}$, and filter inductance is $L=$
$0.2 \mathrm{mH}$. The grid-connected inverter control system's active power outer control loop PIR regulator parameters are $P=$ $10, I=0.01$, and $R=5$; current inner control loop PIR regulator parameters are $P=10, I=0.1$, and $R=5$. The system's reactive power outer control loop PIR regulator parameters are $P=10, I=0.01$, and $R=5$; current inner control loop PIR regulator parameters are $P=10, I=0.1$, and $R=5$.

Assumed that when an asymmetric ground fault occurs in the distribution network, the microgrid should provide additional $15 \mathrm{~kW}$ active power. Now, since China has no requirements for DG possessing LVRT ability in low voltage distribution network, we refer to "LVRT requirements of the photovoltaic power plants in medium voltage distribution network" [8]. We conducted a simulation experiment when single-phase ground fault or two-phase ground fault occurs 
in the distribution network, respectively. Set that the faults occurred in the distribution network in 1 second and the voltage drop down to $20 \%$ for 1 second.

Figures 7 and 8 are simulation waveforms for single-phase ground fault and two-phase ground fault in distribution network respectively. From the simulation waveform we can learn that during the microgrid operation in LVRT status, its reactive power output for distribution network remained stable. Due to the energy storage system's active power output increase, microgrid's power output increased to $100 \mathrm{~kW}$, providing support for distribution network fault recovery. As soon as the fault in the distribution network is eliminated, the power passing through PCC returned to normal. Although the microgrid main feeder voltage drop caused the submicrogrid A's power output to decrease, this energy was absorbed by its internal super capacitor. Hence power in sub-microgrid A can maintain a balance. PIR regulators utilized in the grid-connected inverter control system suppressed power output fluctuations. And the super capacitor bidirectional converter maintained the sub-microgrid DC bus voltage. Hence, during the microgrid operated in LVRT status, the sub-microgrid DC bus voltage fluctuations can be greatly inhibited. The sub-microgrid A's DC bus voltage had no significant fluctuations, providing a strong guarantee for the load. We can also learn that the power dissipated by DC load and AC load maintained stability. The loads had almost not been impacted from microgrid main feeder voltage drop.

\section{Conclusion}

We designed a microgrid with a LVRT capability for the first time. Simulations for single-phase ground fault and twophase ground fault in distribution network are implemented in PSCAD/EMTDC. From the simulation results, the following conclusions can be drawn.

(1) The designed microgrid consists of several DC submicrogrids and hybrid energy storage system. One of the main advantages of the DC microgrid is that it can save a lot of electronic devices. Therefore, the microgrid described in this paper also has this advantage.

(2) The microgrid we designed can maintain DG and load operation normally when an asymmetry ground fault occurs in the distribution network. In this case, DG and load need not to be removed. The microgrid has a LVRT capability.

(3) During the microgrid operation in LVRT status, it exports active power according to the distribution network's requirement, providing support for the distribution network's fault recovery.

(4) Because the distribution network's fault phase voltage drop deeper and frequency of power harmonic is too high in the experiment and other reasons, power fluctuations near PCC are not well suppressed. We must take measures to improve for it in the future.

\section{Conflict of Interests}

The authors declare that there is no conflict of interests regarding the publication of this paper.

\section{Acknowledgment}

This work is supported by National Natural Science Foundation of China (51177015).

\section{References}

[1] S. A. Aoyang, D. Xing, W. Minghao et al., "To response the high penetration of micro power in grid network access," Automation of Electric Power Systems, vol. 34, no. 1, pp. 78-83, 2010.

[2] S. Huang, L. Xiao, K. Huang, Z. Chen, and S. Xiong, "Operation and control on the grid-side converter of the directly-driven wind turbine with PM synchronous generator during asymmetrical faults," Transactions of China Electrotechnical Society, vol. 26, no. 2, pp. 173-180, 2011.

[3] S.-Y. Hou, Y. Fang, J.-X. Zeng, and Z.-N. Yin, "Application of supercapacitors to improve wind power system's low voltage ride through capability," Electric Machines and Control, vol. 14, no. 5, pp. 26-31, 2010.

[4] C. Zhang, J. Zhang, W. Wu, and D. Xu, "High-frequency link inverter waveform control with resonant controller based on delta operator," Transactions of China Electrotechnical Society, vol. 23, no. 7, pp. 81-85, 2008.

[5] P. C. Loh, M. J. Newman, D. N. Zmood, and D. G. Holmes, "A comparative analysis of multiloop voltage regulation strategies for single and three-phase UPS systems," IEEE Transactions on Power Electronics, vol. 18, no. 5, pp. 1176-1185, 2003.

[6] D. N. Zmood and D. G. Holmes, "Stationary frame current regulation of PWM inverters with zero steady-state error," IEEE Transactions on Power Electronics, vol. 18, no. 3, pp. 814-822, 2003.

[7] L. Wenbin, Research on Energy Storage Systems to Stabilize Wind Farm Power Fluctuations, Chongqing University, Chongqing, China, 2012.

[8] Photovoltaic power plants connected to the grid technology technical requirements of State Grid Corporation (Trial), 2009. 


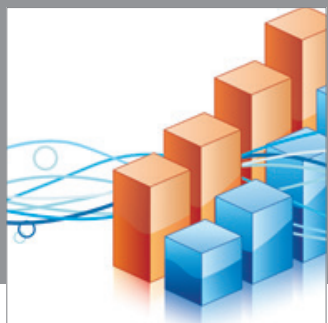

Advances in

Operations Research

mansans

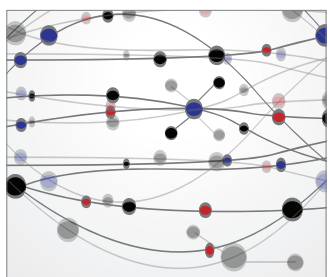

The Scientific World Journal
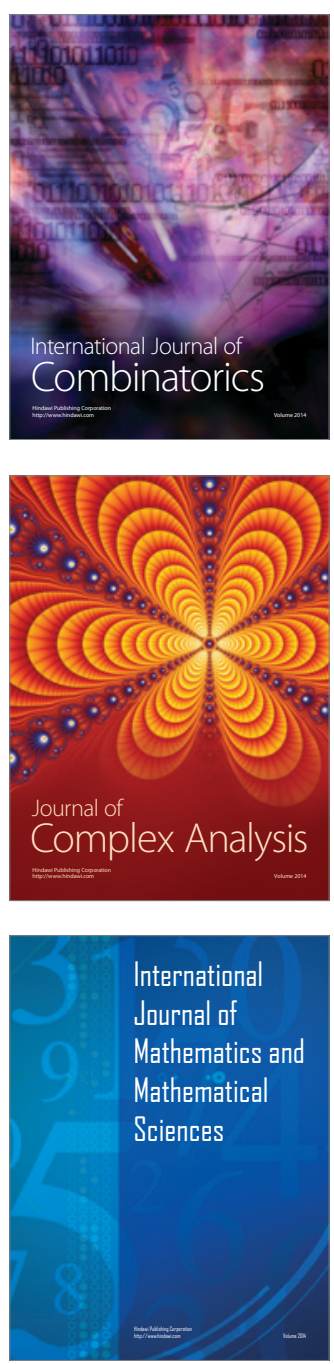
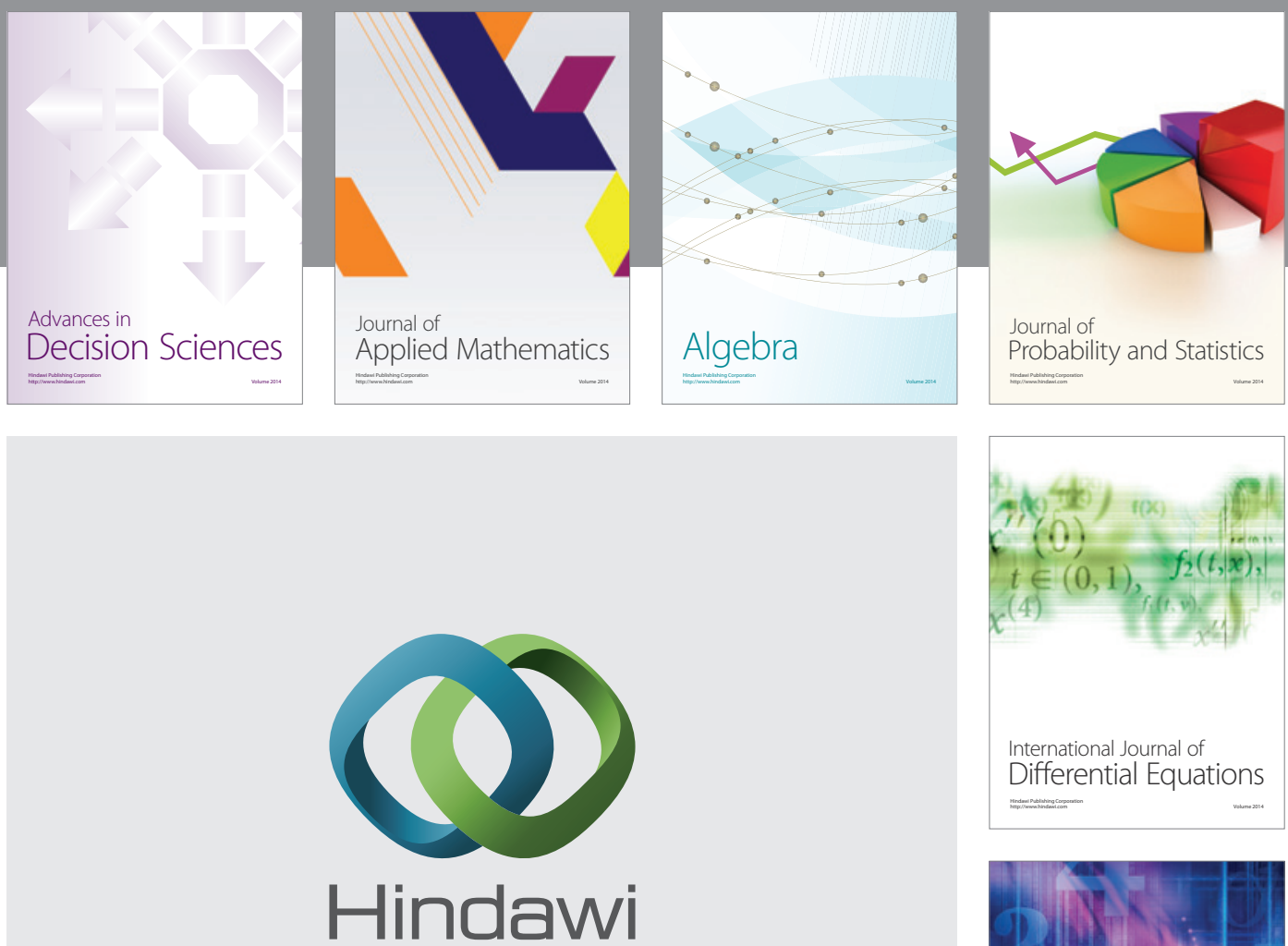

Submit your manuscripts at http://www.hindawi.com
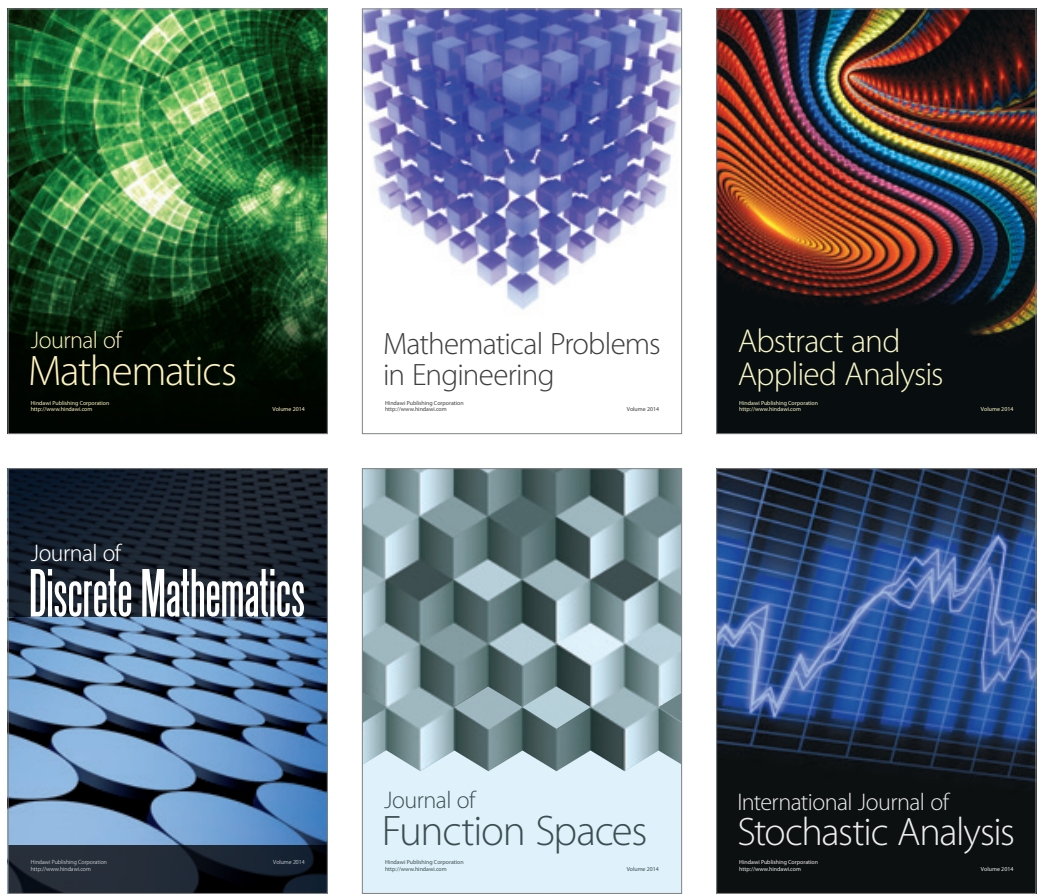

Journal of

Function Spaces

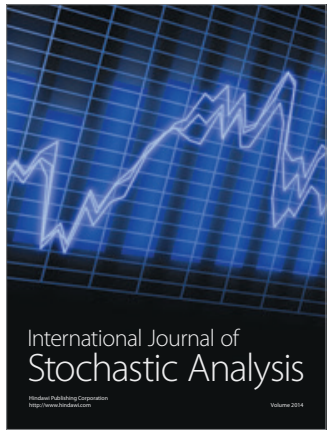

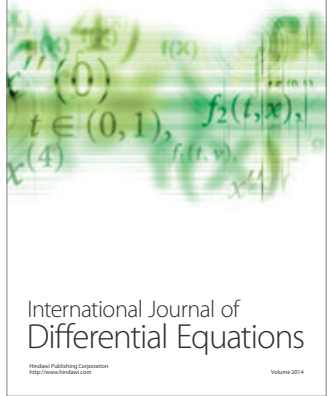
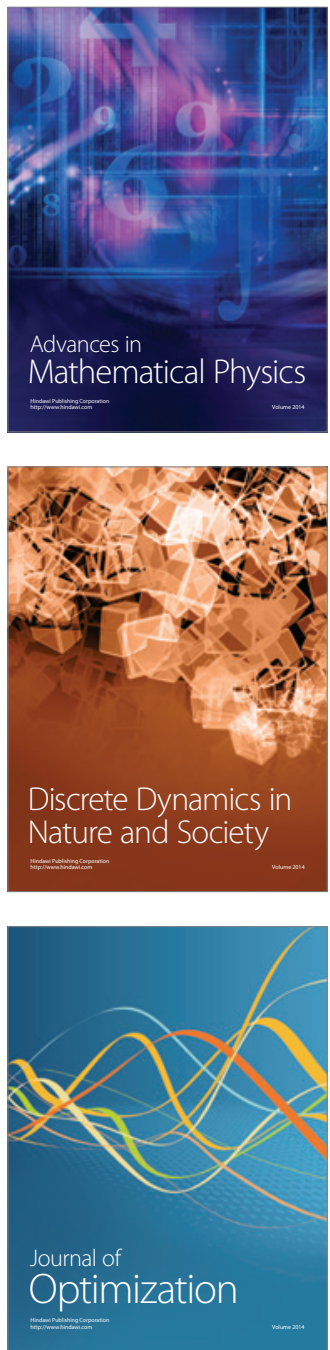